\title{
The Mark of the Millennial: Reshaping Healthcare Education and Delivery
}

Darshana Shah, $\mathrm{PhD}^{1}$

\section{Author Affiliations:}

1. Marshall University Joan C. Edwards School of Medicine, Huntington, West Virginia

The author has no financial disclosures to declare and no conflicts of interest to report.

\section{Corresponding Author:}

Darshana Shah, $\mathrm{PhD}$

Associate Dean

Office of Faculty Advancement

Professor, Department of Pathology

Marshall University Joan C. Edwards School of Medicine

1600 Medical Center Drive

Huntington, WV 25701

Email: shah@marshall.edu 
An influx of millennials is reshaping the workplace 1 - including the practice of medicine and the development of physicians in training. The attitudes, influences, and behaviors of millennials do not align with traditional models of healthcare delivery or healthcare education.

Millennials in academic medicine represent the majority of medical students, residents, and a small percentages of junior faculty. In the consumer world, millennial patients are also changing the culture of healthcare industries. ${ }^{2}$ The millennial that grew up with broadband, smartphones, tablets and social media expects instant access to information and now infuses medicine with their attitudes, aspirations, and experiences. They have come to the platform with new ideas, new needs, and new challenges of shaping the culture of accountability and feedback. The rapid pace of culture of change makes generations diverge. The intangible tension between highly experienced predecessor generations (Boomers \& Generation X) and digitally savvy, collaborative millennials has been a subject of intense discussion. However, the intergenerational tensions that do appear can often be explained by a lack of understanding between generations. Mutually satisfying partnerships in both education and clinical arenas can be established by learning more about what motivates and is significant to millennials and approaching the process with an open mind. In turn, this will improve the learning environment for all generations, while ultimately improve patient care.

Millennials have specific needs and expectations of their learning and career development. ${ }^{3}$ They are explorative, experiential and hands-on; they prefer to learn by doing rather than by being told what to do. ${ }^{4}$ One of the strongest millennial characteristics is that they welcome and expect detailed, regular, well-timed, and structured feedback and appreciate commendation for a job well done. One successful way to work with millennial learners is to set clear goals for continous learning and to provide regular feedback given in a coaching style along with positive reinforcement. ${ }^{5}$ This is best achieved by investing time and interest in millennial learners.

Mentoring is important to this generation, and many respond well to senior faculty. However, to keep them engaged, mentoring can not be in the traditional ways we have all come to know. Millennials believe that mentoring can happen anywhere and from anyone. They see the inherent value in others and, as a result, are open to learning from those around them. Mentoring models such as group mentoring, peer mentoring and reverse mentoring pair well with the millennial mentality. You will tap into a generation that is resourceful, innovative, efficient, and ethical and that will thrive when they see faculty mentors and coaches who are genuinely interested and invested in their success.

Projected physician shortage in the workforce ${ }^{6}$ is making retention and satisfaction of millennials a top priority. There is a significant gap between what millennials want and expect from their employer. Millennials expect to work hard and are drawn to organizations that offer a comfortable, engaging and inspiring atmosphere that creatively integrates work and life. In this era of millennials generation hierarchies have to disappear; millennials respect credentials behind the name but connect to the leaders who are approachable, supportive and good motivators. Millennials anticipate working in communities of mutual interest and passion. Consequently, people management strategies of human resources must be replaced with empowering talent strategies. Traditional perks used to recruit and retain top talent may no longer just depend on the compensation package, but rather on the sense of belonging to an 
organization that offers opportunities for growth and personalized professional development which is relevant and applicable to their targeted future professional growth. They seek a longterm relationship, based on intergrity, transparency, and trust with their employer.

As consumers, millennial patients prioritize convenience and preventive health. ${ }^{7}$ Millennials believe in getting health care delivered more quickly and efficiently. They have a different perspective of what affects their health and wellness compared to their predecessors. The millennial generation does not immediately turn to primary care physicians as older generation do in regard to non-critical health concerns. The newer generation accesses online self-help resources to take control of their healthcare. They are more likely to focus on day-to-day health maintenance choices that they believe will pay off long-term. Millennials also rely on what other patients have to say about their experiences since their generation is increasingly comfortable sharing their symptoms and treatment experiences through patient networks. They thrive on technology but still demand genuine human interactions. From a physican standpoint, spending a few extra minutes getting to know millennials and making them not just another patient or a list of symptoms on a chart will facilitate a meaningful doctor-pateint relationship and bring success to the practice.

In sum, millennials' views are powerfully shaped by having the World Wide Web at their fingertips. This generation's behavior is starting to make its mark in the healthcare field and is anticipated to lead to even larger changes as millennials take on increasing roles as healthcare students, providers, faculty, and consumers.

\section{References}

1. Millennials surpass Gen Xers as the largest generation in. PEW Research Center http://www.pewresearch.org/fact-tank/2015/05/11/millennials-surpass-gen-xers-as- (accessed April 26, 2017).

2. Millennial Mind-Set: Pursuing the Next Generation of Consumers, http://www.jacr.org/article/S15461440(15)00194-5/pdf (accessed April 26, 2017)

3. Twelve tips for facilitating Millennials' learning. David h. Roberts, Lori r. Newman \& Richard m. Schwartzstein. Medical Teacher.. 1-5. 2012

4. Multigenerational Challenges and the Future of Graduate Medical Education. Philip G. Boysen, II, MD, MBA, FACP, FCCP, FCCM, Laurie Daste, MD, Theresa Northern, DO, MPH. Ochsner Journal 16:101107,2016

5. Teaching and Working With Millennial Trainees: Impact on Radiological Education and Work Performance. Ana P. Lourenco, MD, John J. Cronan, MD. J Am Coll Radiol 2017;14:92-95

6. Physician Shortage and Projections The 2017 Update: https://www.aamc.org/data/workforce/reports/439206/physicianshortageandprojections.html (accessed April 29, 2017)

7. Millennial Mind-Set: Pursuing the Next Generation of Consumers. Tina Wells, Elliot K. Fishman, MD, Karen M. Horton, MD, Siva P. Raman, MD. . J Am Coll Radiol. 2015 Jul;12(7):742-4. 